opportunity to be an integral part of a football club as well as being a fan. There are spin-offs such as providing medical cover when the stadium is used for other activities. Personally, I have supported Elton John \& Oasis in concert, watched Rugby League test matches and enjoyed the Commonwealth Games.

The provision of pre-hospital care is an interesting addition to mainstream general practice. It helps to maintain clinical skills.

For sporting fans it can also be an ideal opportunity to get closer to the action and actually participate rather than merely observe.

\section{FURTHER READING}

Dignon and Hearns. Event Medicine 323(7326):S2-7326. BMJ Career Focus

Health and Safety Executive. The event safety guide. London; 1999

Doctor's assistance to sports clubs and sporting events. British Medical Association. www.bma.org.uk

The Hillsborough Stadium Disaster: 15 April 1989. Inquiry by Lord Justice Taylor: Final Report. London: HMSO; 1997

\title{
THE VIRTUAL CONSULTATION
}

\section{Marwan Bukhari; Rakshi Memon; John Halsey}

The Rheumatology Department at the Royal Lancaster Infirmary has won the $\mathbf{2 0 0 5}$ Wyeth Innovations Award, which was awarded for the innovation of email communication and support between the general practitioners (GPs) and the consultant rheumatologists.

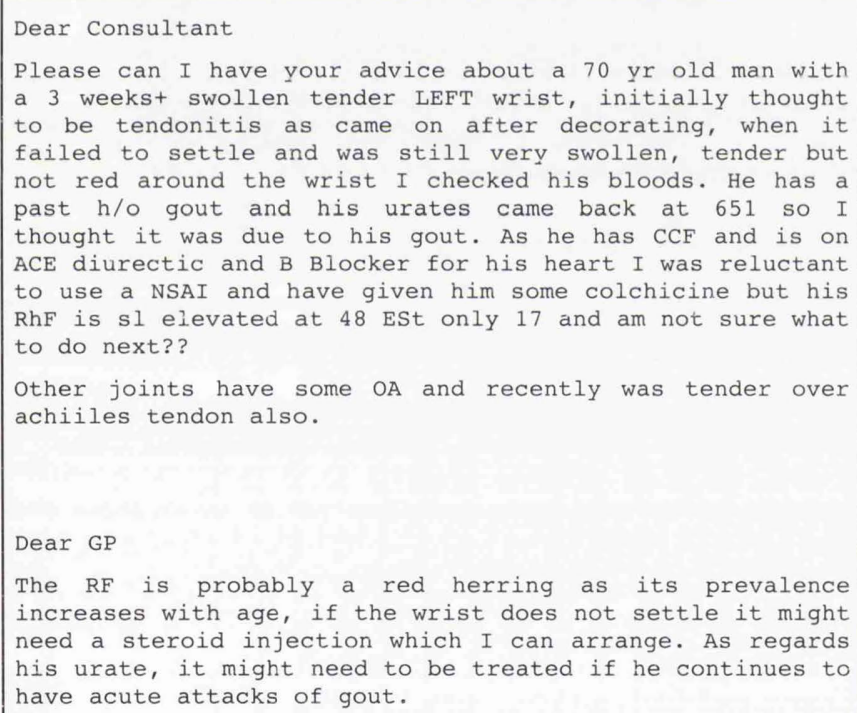

There is an impression that not all referrals to rheumatology clinics require an outpatient appointment as some cases could be managed in primary care with appropriate advice and guidance. As a pilot site for the Action on Orthopaedics Programme, which is part of the NHS Modernisation Agency, we have developed an email advice service for GPs in Morecambe Bay (population 312,000).

\section{METHODS}

In collaboration with the Primary Care Trust (PCT), Morecambe Bay Hospitals Trust and information technology department a secure email advice clinic was established and a pilot clinic commenced in November 2001. Email enquiries from GPs are dealt with in a weekly clinic by a consultant rheumatologist $(\mathrm{MB})$. A survey of the first 84 referrals was made.

\section{RESULTS}

Fifty-three $(63 \%)$ of the referrals were dealt with in primary care following advice and guidance and only $31(37 \%)$ needed referral to secondary care. Of these, $21(68 \%)$ were seen in the Rheumatology Department and ten $(32 \%)$ in the Orthopaedic or Neurology Departments. The time needed to answer emails was considerably less than the time it would have taken to see these patients in secondary care. Additionally, the consultant advice was received quicker than it would have been done by traditional means. Very positive feedback has been received from GPs about the collaborative innovation with a request that a similar service be provided by other specialties.

The consultant answers emails on a daily basis, with queries ranging from specific questions about patients not seen yet and in whom the management is doubtful to established patients who have developed new problems. It allows a pro-active, fast and efficient method of communication. Additionally, there is an element of education as patients are managed interactively and results are requested and reviewed jointly between primary and secondary care.

This has garnered a lot of support and indeed there has been a request from the PCT that an email advice service for GPs should be expanded throughout the other specialities. Within the Rheumatology Department the service has also been extended to include community physiotherapists. The department was chosen from a shortlist of five hospital trusts by the awards committee on Tuesday, 19th April, 2005. The judging panel included professors of rheumatology, specialist nurses and patient representatives.

\section{CONCLUSIONS}

This survey has confirmed that an electronic advice service is a valuable means of improving the management of musculoskeletal diseases in primary care with the potential to reduce referrals for outpatient appointments.

An audit of this service has previously been presented as a poster at the British Society for Rheumatology meeting in 2003. (Rheumatology 2003:42(Supp 1);69) 